\title{
Gillies fan flap for the reconstruction of an upper lip defect caused by noma: case presentation
}

This article was published in the following Dove Press journal:

Clinical, Cosmetic and Investigational Dentistry

30 May 2012

Number of times this article has been viewed

\section{Seidu Adebayo Bello \\ Department of Dental and Maxillofacial Surgery, State House Medical Center, Asokoro, Abuja, Nigeria}

Correspondence: Seidu Adebayo Bello Consultant Oral and Maxillofacial Surgeon, State House Medical Center, PMB 316, Asokoro, Abuja, Nigeria Tel +2348054929034

Email sabello2004@yahoo.com

\begin{abstract}
The case of a 65-year-old noma patient with a defect involving her upper lip is presented. The defect also included missing teeth numbers eleven, twelve, 21, and 22 and the adjoining alveolus. One-stage lip reconstruction was carried out with Gillies fan flap followed by vestibuloplasty and commissuroplasty. An acrylic partial denture was subsequently fabricated to replace the missing teeth and thereby restore function. Even though the incidence of cancrum oris has reduced worldwide, cases are still being reported in Africa and can leave behind a significant facial defect. Whereas most cases of lip defects reported from the Western world are due to cancer, cancrum oris could be the cause of lip defects in sub-Saharan Africa. Gillies fan flap could be employed for the reconstruction of a relatively large defect of the lip and the disadvantage of microstomia could be minimized for the restoration of articulation, speech, and masticatory functions of the lip.
\end{abstract}

Keywords: Gillies fan flap, reconstruction, upper lip, noma

\section{Case presentation}

A 65-year-old female patient presented with a defective upper lip. There was history of childhood oral infection that progressed to involve the upper lip. Examination revealed the patient was systemically stable except for the defective upper lip. About $70 \%$ of the upper lip was missing, with involvement of the alveolus up to the base of the columella. The upper lip defect extended from a point $2 \mathrm{~mm}$ above the right commissure to a point about $10 \mathrm{~mm}$ to the left commissure. The teeth missing were numbers 11, 12, 21, and 22 (Figure 1). A diagnosis of post cancrum oris with attendant lip and alveolar defect was made.

Under local anesthesia and mild sedation, upper lip reconstruction was carried out using a Gillies fan flap. Local anesthesia was achieved with a $\%$ Xylocaine ${ }^{\circledR}$ with 1:100,000 adrenaline; sedation was achieved using intravenous $10 \mathrm{mg}$ diazepam and $30 \mathrm{mg}$ pentazocine.

Gillies flap is a rectangular full thickness flap involving the skin, the muscle, and oral mucosa with the melolabial crease being the lateral limit (Figure 2). The vertical width was determined by the height of the defect. Raising the flap was preceded by deepithelialization of the defect. The flap was sutured in three layers: mucosa, muscle, and skin. The flap took well and the patient did well thereafter. Mild respiratory distress was a major complication occasioned by the newly experienced anterior oral seal. The patient had a second surgery 8 weeks later where cheiloplasty and vestibuloplasty was carried out. The patient became more comfortable with the new lip. 


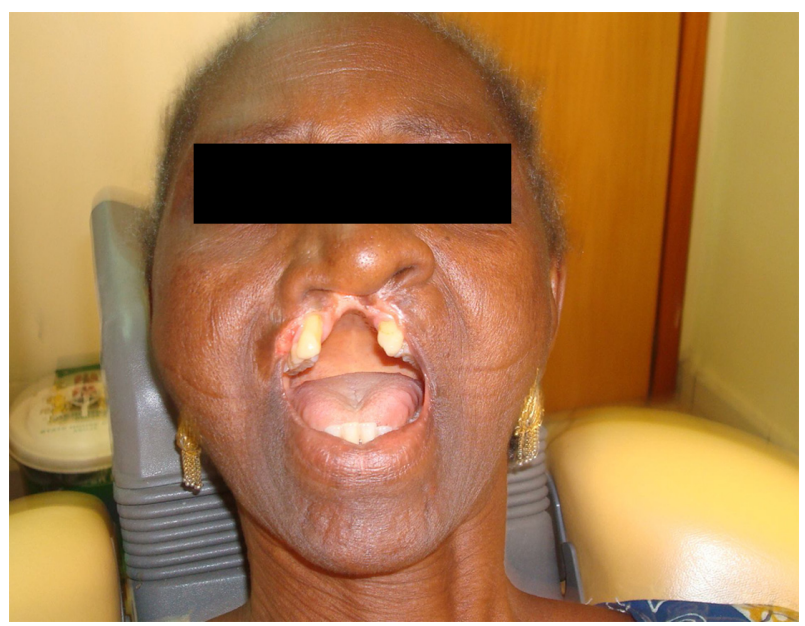

Figure I Upper lip defect, adjoining alveolus, and missing teeth.

Five months later a commissuroplasty was done. A triangular incision of about $1 \mathrm{~cm}$ long was made on the commissure bilaterally, and skin to mucosa suturing was done. Increased mouth opening was observed (Figure 3). Restoration of muscle and sensory innervations was noticed at 6 months postsurgery.

Two weeks later, an acrylic removable partial denture replacing teeth numbers $11,12,21$, and 22 was fabricated (Figure 3).

Thereafter, the patient experienced both physical and functional improvement (Figures 3 and 4).

\section{Discussion}

Noma (cancrum oris) is a spreading gangrene that invades the facial tissues. ${ }^{1}$ Pathogenetically, noma is the result of a high bacterial load of normal microorganisms in the mouth that breaks down the resistance of a failing immune system. This leads to a spreading gangrene that quickly invades

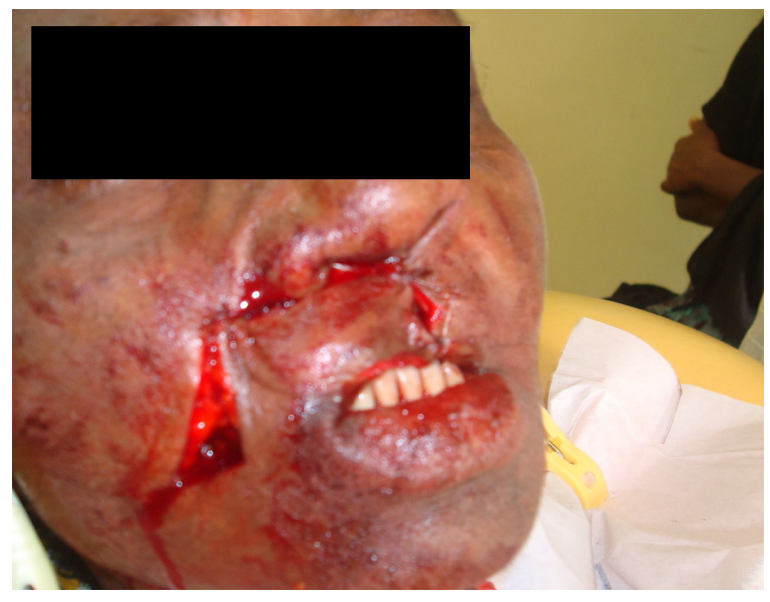

Figure 2 A rectangular Gillies fan flap that is raised and inserted to the recipient bed.

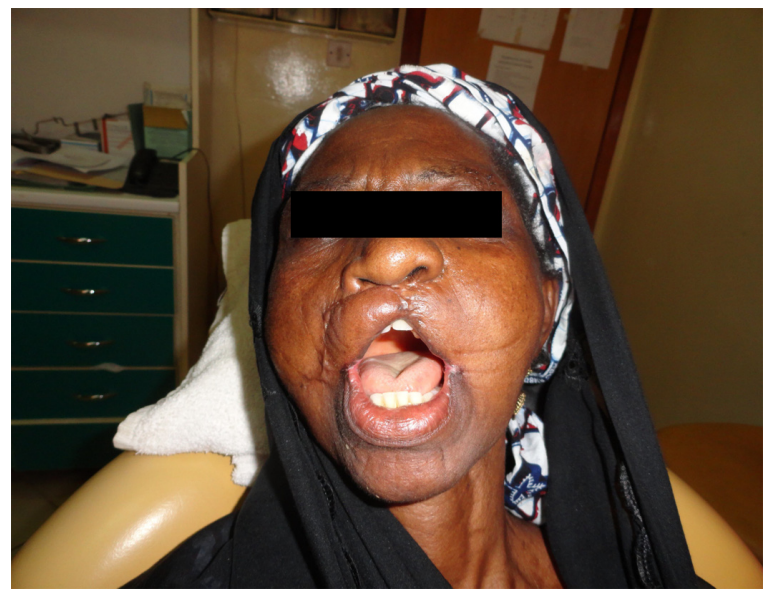

Figure 3 Reconstructed lip and fabricated teeth in situ showing improved mouth opening.

the facial tissues and leads to severe facial disfigurement, ankylosis of the temporomandibular joint, oral incontinence, and problems with speech. ${ }^{2,3}$

While tracing the history of noma, Marck ${ }^{1}$ stated that it had been eliminated from developed countries by the end of 19th century but still persisted in Africa and Asia due to extreme poverty. It is an escalating public health problem among impoverished children in the developing world, particularly in sub-Saharan Africa where the incidence in some countries is estimated to be $12 / 1000$ cases in the most affected communities. ${ }^{3}$ Even though cancrum oris is hardly mentioned as a cause of lip defects requiring reconstruction in developed countries, it is a major cause in developing countries.

The patient under review grew up in a poor rural area of Nigeria and only presented at 65 years of age with a facial defect at an outreach program that offered free surgical services. She'd experienced a gum disease associated with fever and general malaise at the age of 4 years which

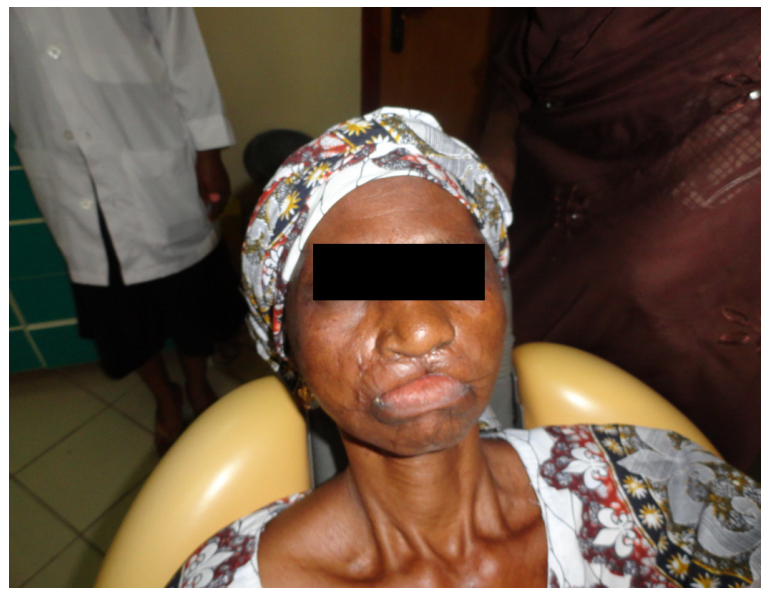

Figure 4 Reconstructed lip showing improved physical appearance. 
progressed to involve the upper lip, alveolus, and loss of associated teeth. Although fresh cases are not common in Nigeria presently, old cases still present with facial deformities (Figure 1) especially at outreach programs where free services are available. This phenomenon is due to poverty, ignorance, and inaccessible healthcare. Access to healthcare is still poor in Nigeria due to poverty and a limited health insurance system. ${ }^{3}$ Noma has been described as an oral lesion that progresses to involve the perioral tissues; ${ }^{2}$ the author has, however, observed a number of cases with only nasal defect without oral involvement. It could therefore be postulated that some cases of noma originate from nasal mucosa following immunosuppression.

The primary objective of a reconstructive effort is an aesthetic result that approaches a normal appearance. The aims of lip reconstruction should be to maintain oral competence, maintain maximum oral aperture, maintain mobility, maintain sensation when possible, and maximize cosmesis. ${ }^{4,5}$

Several authors have described different techniques for the reconstruction of the lip with the latest being the use of microvascular tissue transfer. In the 1920s, Gillies described a classic fan flap using a full-thickness pedicle that allows redistribution of the remaining lip during the reconstructive effort and emphasized the use of a similar or like tissue. Gillies fan flap is a circumoral advancement rotation flap, based on labial vessels, that advances the ipsilateral remaining lip segment with a portion of the opposing ipsilateral lip (Figure 2). ${ }^{4}$

The choice of reconstruction technique is influenced by size of the defect, the color match of the donor site, operator preference, technical capability, and aesthetic requirement. The fan flap used in the case under review was a rectangular full-thickness, through-and-through excision of the entire lip into the oral cavity that can be used for a lip defect involving up to $70 \%$ of the lip. It also has the advantage of being a single stage procedure. Being a local flap, it has a good color match as experienced in this patient.

Following the surgery in the patient under review, the commissure was shifted from its natural position, causing it to become rounded, and there was attendant microstomia. Commissuroplasty brought some improvement and allowed for the subsequent fabrication of a partial denture to replace the lost teeth. Commissuroplasty can be accomplished by resecting the blunted portion of the commissure and advancing buccal mucosa into the defect to recreate a more naturally appearing commissure. ${ }^{4}$ However, care must be taken during the procedure to avoid excessive disruption of the orbicularis musculature that could result in oral incompetence. ${ }^{5}$
Lip denervation is another disadvantage of this procedure. Return of sensory function may begin after several months, usually in this order: pain, touch, and temperature; hypersensitivity of the flap may also occur but usually resolves after the first year. ${ }^{4}$ Motor and sensory reinnervations have been reported to occur 6-18 months postsurgery. ${ }^{6}$ Even though serial testing was not carried out on this patient, sensory and motor innervations were observed to have been reestablished at 6 months postsurgery.

Upper lip defects pose a greater challenge for an optimal reconstruction because of the surface topography, complexity of the anatomy, and potential for distorting the upper lip subunits, thus creating a noticeable asymmetry. ${ }^{5}$ In addition, a lip defect caused by cancrum oris is characterized by irregular edges and can be associated with significant scarring, which is a challenge to the reconstructive effort. The lip switch flap popularized by Abbe and Estlander could have been an option in this case but this procedure is indicated in a defect of one-half to two-thirds of the lip. ${ }^{6,7}$ It requires a second stage to detach the flap pedicle and it is contraindicated in patients who can't tolerate keeping the mouth closed for 2-3 weeks. The anterior oral seal created by this newly constructed lip resulted in a serious discomfort for the patient under review with some reported nocturnal apnea attacks. The initial discomfort resolved following adjunctive sulcoplasty. Advancement flap has been used for the reconstruction of columella, membranous septum, and upper lip in a single stage operation, ${ }^{8}$ but was not preferred by the author. The Abbe flap was considered as an adjunct to improve on the lip height and general appearance, but in addition to doubting the patient's capacity to tolerate the flap, she was satisfied enough with the new appearance not to subject herself to another surgery.

Microvascular tissue transfer for lip reconstruction has become popular in recent times. Lower lip defects involving less than $80 \%$ of the width of the lip can be reconstructed effectively with a local flap but when the amount of tissue resected includes the entire lip mass and encroaches on the chin, distant tissue should be considered. ${ }^{9}$ A radial forearm flap with palmaris longus tendon, chimeric lateral femoral circumflex perforator flap, and a free temporal scalp flap have been used for lip reconstruction; ; 10 however, it is of note that the lip defects referred to were due to cancer with no reference to infection, showing its apparent nonexistence. In sub-Saharan Africa, on the other hand, lip defects could be caused by cancrum oris. With a defect of about $70 \%$, the local flap employed in the present case was appropriate. Additionally, it is a less technical technique that is easily affordable in a resource-limited environment. 
Even though the end result might not be a perfect lip, the facial improvement and functional restoration occasioned by the new lip and fabrication of teeth was applauded by the patient's relatives (Figures 3 and 4).

\section{Conclusion}

Even though the incidence of cancrum oris has reduced worldwide, cases are still being reported in Africa and can leave behind a significant facial defect. Whereas most cases of lip defects reported from the western world are due to cancer, cancrum oris could be the cause of lip defect in Sub-Saharan Africa. Gillies fan flap can be employed for the reconstruction of a relatively large defect of the lip and the disadvantage of microstomia can be minimized for the restoration of articulation, speech, and masticatory functions of the lip.

\section{Acknowledgments}

Consent has been obtained for using patient's photographs. I hereby acknowledge Dr SO Ajike for his review and useful contribution.

\section{Disclosure}

The author reports no conflicts of interest in this work. This paper was presented at: Chang Gung Forum 2011, 3rd International
Workshop on Surgical-Orthodontic Approach to Dentofacial Deformity; 2011 October 31-November 2; Taipei, Taiwan.

\section{References}

1. Marck KW. A history of noma, the "Face of Poverty." Plast Reconstr Surg. 2003;111(5):1702-1707.

2. Enwonwu CO, Falkler WA Jr, Idigbe EO, et al. Pathogenesis of cancrum oris (noma): confounding interactions of malnutrition with infection. Am J Trop Med Hyg. 1999;60(2):223-232.

3. Bello SA, Aluko Olokun B, Olaitan AA, Ajike SO. Aetiology and presentation of ankylosis of the temporomandibular joint: report of 23 cases from Abuja, Nigeria. Br J Oral Maxillofac Surg. 2012;50(1):80-84.

4. Renner G. Reconstruction of the lip. In: Local Flaps in Facial Reconstruction. Baker SR, Swanson NA, editors. St Louis, MO: Mosby; 1995:345-396.

5. Galyon SW, Frodel JL. Lip and perioral defects. Otolaryngol Clin North Am. 2001;34(3):647-666.

6. Bailey BY, Calhoun KH. Atlas of Head and Neck Surgery Otolaryngology. Philadelphia, PA: Lippincott Williams \& Wilkins; 2001:42-65.

7. Coppit GL, Lin DT, Burkey BB. Current concepts in lip reconstruction. Curr Opin Otolaryngol Head Neck Surg. 2004;12(4):281-287.

8. Akbas H, Keskin M, Guneren E, Eroglu L, Demir A. Reconstruction of columella, membranous septum, and upper lip in a single stage operation. Br J Plast Surg. 2003;56(3):291-292.

9. Serletti JM, Tavin E, Moran SL, Coniglio JU. Total lower lip reconstruction with a sensate composite radial forearm-palmaris longus free flap and a tongue flap. Plast Reconstr Surg. 1997;99(2):559-561.

10. Huang WC, Chen HC, Jain V, et al. Reconstruction of through-andthrough cheek defects involving the oral commissure using chimeric flaps from the thigh lateral femoral circumflex system. Plast Reconstr Surg. 2002;109(2):433-443.
Clinical, Cosmetic and Investigational Dentistry

\section{Publish your work in this journal}

Clinical, Cosmetic and Investigational Dentistry is an international, peer-reviewed, open access, online journal focusing on the latest clinical and experimental research in dentistry with specific emphasis on cosmetic interventions. Innovative developments in dental materials, techniques and devices that improve outcomes and patient satisfac-

\section{Dovepress}

tion and preference will be highlighted. The manuscript management system is completely online and includes a very quick and fair peerreview system, which is all easy to use. Visit http://www.dovepress. com/testimonials.php to read real quotes from published authors. 